\title{
Editorial for Special Issue "Remote Sensing for Monitoring Wildlife and Habitat in a Changing World"
}

\author{
Andrés Viña 1,2
}

1 Center for Systems Integration and Sustainability, Department of Fisheries and Wildlife, Michigan State University, Lansing, MI 48823, USA; vina@msu.edu

2 Geography Department, University of North Carolina, Chapel Hill, NC 27599, USA

Citation: Viña, A. Editorial for Special Issue "Remote Sensing for Monitoring Wildlife and Habitat in a Changing World". Remote Sens. 2021, 13, 2762. https://doi.org/10.3390/ rs13142762

Received: 1 July 2021

Accepted: 3 July 2021

Published: 14 July 2021

Publisher's Note: MDPI stays neutral with regard to jurisdictional claims in published maps and institutional affiliations.

Copyright: (c) 2021 by the author Licensee MDPI, Basel, Switzerland. This article is an open access article distributed under the terms and conditions of the Creative Commons Attribution (CC BY) license (https:// creativecommons.org/licenses/by/ $4.0 /)$.

\section{Introduction}

Escalating human impacts on the Earth are creating unprecedented challenges, including the drastic degradation and loss of biodiversity worldwide. As human activities are powerful forces of change and degradation, causing about $25 \%$ of plant and animal species to be at risk of extinction over the past 50 years [1], it is imperative to obtain timely and up-to-date information on the abundance and distribution of species and their temporal dynamics, particularly for establishing successful conservation approaches. Such detailed information is prohibitively expensive to obtain through traditional field surveys due to their infrequent nature, together with their limited spatial extents. Thus, recent advances in remote sensing have become crucial for obtaining such information across broad geographic extents and at shorter and more frequent temporal intervals. Based on a combination of in situ and remote sensing data and analytics, such approaches open new windows of opportunity for not only expanding our knowledge of biodiversity, but also for evaluating the processes structuring its spatio-temporal dynamics, including the impact of human activities.

Many attempts to assess biodiversity patterns through remote sensing techniques have relied on the relationships between species diversity and land cover obtained from the numerical classification of remotely sensed data. While useful, information acquired through such relationships may be insufficient for assessing biodiversity patterns, particularly within individual land cover types, which by definition are assumed to be spatially homogeneous while in reality they are heterogeneous. Alternative studies have discerned pixel-based relationships between patterns of biodiversity across broad geographic regions and multispectral imagery [2]. Other studies have amassed spectral libraries of different species to develop relationships between species diversity and spectral heterogeneity based on hyper-spectral imagery [3], have related species diversity and composition with land surface phenology [4], or have evaluated functional diversity based on remotely sensed data using multicriteria approaches [5]. However, several of these advances, while successful, are constrained to particular geographic locations, species, and/or species assemblages. Therefore, much more research is urgently needed to develop and test effective techniques applicable at multiple scales, in different geographic settings and over time, together with their successful incorporation into ecological research and biodiversity conservation.

\section{Scope of the Special Issue}

The works included in this Special Issue present some scientific and technological innovations in remote sensing for assessing the spatio-temporal dynamics of wildlife species and their habitats. Although constituting a very small set of studies, they cover a diverse array of geographic settings distributed throughout the world and comprising both terrestrial $[6-14]$ and aquatic $[9,12,15,16]$ systems (Figure 1 ). They also evaluate individual species groups, including corals [15], reptiles [6,9], birds [7,10], mammals $[8,11,13,14]$, or a combination of different species groups $[12,16]$. These studies used diverse analytical 
approaches applied to remotely sensed data acquired by different sensor systems at different scales ranging from high spatial resolution sensors onboard unoccupied aircraft vehicles [16], underwater systems [15], and space-borne vehicles [12], to intermediate spatial resolution multispectral imagery acquired by operational satellite sensor systems such as the Landsat $[6-8,10,11,14]$, SPOT [7], and MODIS [8,13] satellite series, together with coarser spatial resolution data acquired by weather satellite systems [9]. This diverse array of sensors and analytical approaches proved useful for evaluating habitat requirements and distribution $[7,8,10,12,16]$, species distribution and occurrence [11,15], population dynamics [7], human-wildlife conflicts [13,14], the negative impacts of natural [9] and human-driven [8] disturbances on species distribution, and for assessing the potential impacts of climate change [6].

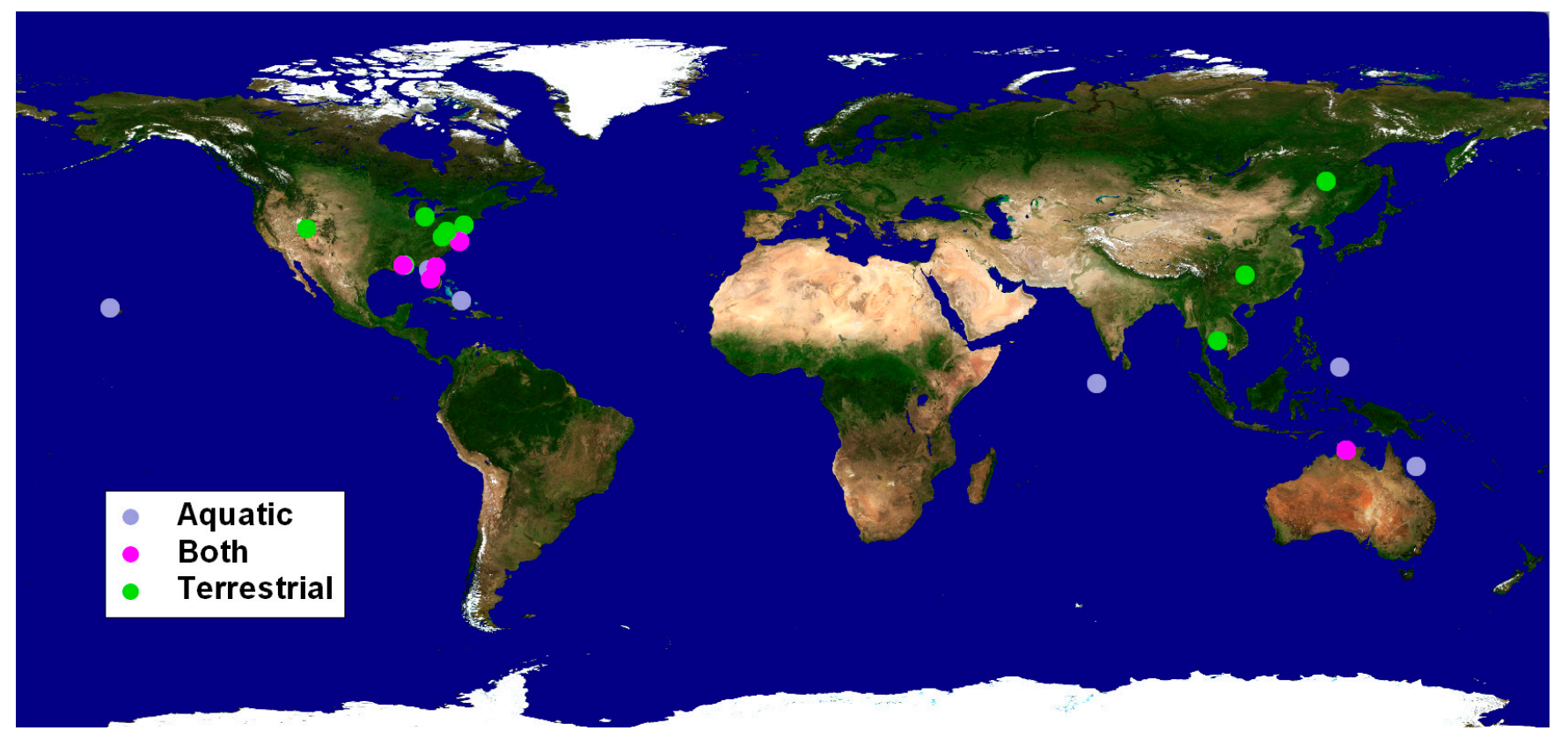

Figure 1. Map highlighting the geographic distribution of the study areas of the articles comprising the Special Issue, and the type of ecosystems (i.e., aquatic, terrestrial or both) involved.

\section{Conclusions}

The scientific and technical information generated by the articles in this Special Issue not only expand methodological frontiers for the incorporation of remotely sensed data into biodiversity research, but also have direct implications for biodiversity conservation at multiple spatial and temporal scales. As such, these studies represent a microcosm of the range of possibilities provided by remote sensing for studying not only the occurrence and distribution of wildlife species and their habitats, but also their changes through space and time. Such approaches also proved suitable to be incorporated into management and conservation. Given the current trends of biodiversity loss and degradation, together with the development of evermore refined sensor systems, this is a crucial and dynamic time for biodiversity research aided by the spatial and temporal scopes uniquely provided by current remote sensors. This also offers many opportunities for addressing complex global sustainability challenges. Therefore, this Special Issue provides a foundation upon which further technological and analytical innovations can be developed, to increase our under-standing of the spatio-temporal patterns of biodiversity and the processes, both natural and human-driven, influencing them.

Funding: This editorial received no external funding.

Acknowledgments: The guest editor would like to thank the authors who contributed to this Special Issue and to all the reviewers who dedicated their time and expertise for providing valuable and 
constructive questions, criticisms and recommendations. The Editorial team of Remote Sensing is also acknowledged for their support.

Conflicts of Interest: The author declares no conflict of interest.

\section{References}

1. Díaz, S.; Settele, J.; Brondízio, E.S.; Ngo, H.T.; Guèze, M.; Agard, J.; Arneth, A.; Balvanera, P.; Brauman, K.A.; Butchart, S.H.M.; et al. Summary for Policymakers of the Global Assessment Report on Biodiversity and Ecosystem Services of the Intergovernmental Science-Policy Platform on Biodiversity and Ecosystem Services; Intergovernmental Science-Policy Platform on Biodiversity and Ecosystem Services (IPBES): Bonn, Germany, 2019.

2. Rochini, D.; Balkenhol, N.; Carter, G.A.; Foody, G.M.; Gillespie, T.W.; He, K.S.; Kark, S.; Levin, N.; Lucas, K.; Luoto, M.; et al. Remotely sensed spectral heterogeneity as a proxy of species diversity: Recent advances and open challenges. Ecol. Inform. 2010, 5, 318-329. [CrossRef]

3. Asner, G.P.; Martin, R.E. Airborne spectranomics: Mapping canopy chemical and taxonomic diversity in tropical forests. Front. Ecol. Environ. 2009, 7, 269-276. [CrossRef]

4. Viña, A.; Liu, W.; Zhou, S.; Huang, J.; Liu, J. Land surface phenology as an indicator of biodiversity patterns. Ecol. Indic. 2016, 64, 281-288. [CrossRef]

5. Cai, D.; Guan, Y.; Guo, S.; Zhang, C.; Fraedrich, K. Mapping plant functional types over broad mountainous regions: A hierarchical soft time-space classification applied to the Tibetan Plateau. Remote Sens. 2014, 6, 3511-3532. [CrossRef]

6. Martin, A.K.; Root, K.V. Challenges and Opportunities for Terrapene carolina carolina under Different Climate Scenarios. Remote Sens. 2020, 12, 836. [CrossRef]

7. Richter, R.; Heim, A.; Heim, W.; Kamp, J.; Vohland, M. Combining Multiband Remote Sensing and Hierarchical Distance Sampling to Establish Drivers of Bird Abundance. Remote Sens. 2020, 12, 38. [CrossRef]

8. Robb, B.; Huang, Q.; Sexton, J.O.; Stoner, D.; Leimgruber, P. Environmental Differences between Migratory and Resident Ungulates-Predicting Movement Strategies in Rocky Mountain Mule Deer (Odocoileus hemionus) with Remotely Sensed Plant Phenology, Snow, and Land Cover. Remote Sens. 2019, 11, 1980. [CrossRef]

9. Fuentes, M.M.; Godfrey, M.H.; Shaver, D.; Ceriani, S.; Gredzens, C.; Boettcher, R.; Ingram, D.; Ware, M.; Wildermann, N. Exposure of Marine Turtle Nesting Grounds to Named Storms Along the Continental USA. Remote Sens. 2019, 11, 2996. [CrossRef]

10. Morris, K.M.; Soehren, E.C.; Woodrey, M.S.; Rush, S.A. Habitat-Suitability Model for the Yellow Rail (Coturnicops noveboracensis) in the Northern Gulf Coast of Alabama and Mississippi, USA. Remote Sens. 2020, 12, 848. [CrossRef]

11. Cove, M.V.; Fergus, C.; Lacher, I.; Akre, T.; McShea, W.J. Projecting Mammal Distributions in Response to Future Alternative Landscapes in a Rapidly Transitioning Region. Remote Sens. 2019, 11, 2482. [CrossRef]

12. Boyden, J.; Wurm, P.; Joyce, K.E.; Boggs, G. Spatial Dynamics of Invasive Para Grass on a Monsoonal Floodplain, Kakadu National Park, Northern Australia. Remote Sens. 2019, 11, 2090. [CrossRef]

13. Kitratporn, N.; Takeuchi, W. Spatiotemporal Distribution of Human-Elephant Conflict in Eastern Thailand: A Model-Based Assessment Using News Reports and Remotely Sensed Data. Remote Sens. 2020, 12, 90. [CrossRef]

14. Giefer, M.; An, L. Synthesizing Remote Sensing and Biophysical Measures to Evaluate Human-wildlife Conflicts: The Case of Wild Boar Crop Raiding in Rural China. Remote Sens. 2020, 12, 618. [CrossRef]

15. González-Rivero, M.; Beijbom, O.; Rodriguez-Ramirez, A.; Bryant, D.E.; Ganase, A.; Gonzalez-Marrero, Y.; Herrera-Reveles, A.; Kennedy, E.V.; Kim, C.J.; Lopez-Marcano, S. Monitoring of Coral Reefs Using Artificial Intelligence: A Feasible and Cost-Effective Approach. Remote Sens. 2020, 12, 489. [CrossRef]

16. Espriella, M.C.; Lecours, V.; Frederick, P.C.; Camp, E.V.; Wilkinson, B. Quantifying Intertidal Habitat Relative Coverage in a Florida Estuary Using UAS Imagery and GEOBIA. Remote Sens. 2020, 12, 677. [CrossRef] 